\title{
Breast cancer and pregnancy
}

\author{
G. K. Azad ${ }^{a}$, A. E. Ring ${ }^{b}$ \\ ${ }^{a}$ Guy's Hospital, St Thomas Street, London, UK; ${ }^{b}$ Royal Sussex County Hospital, Eastern Road, \\ Brighton, UK.
}

\begin{abstract}
Breast cancer is one of the most commonly diagnosed cancers in pregnant women. Diagnosis and treatment in these women are particularly challenging as the necessary investigations and treatment modalities may potentially harm the developing foetus. Nonetheless, it appears that initial diagnostic investigations may be carried out as for non-pregnant women, but bearing in mind the risks of exposing the foetus to ionising radiation. Surgery can be carried out with little risk to the mother or foetus but radiotherapy is generally avoided. Chemotherapy can be given relatively safely when administered after the first trimester, but large volume prospective data and, in particular, data regarding the long-term implications of in utero exposure, are awaited.
\end{abstract}

Keywords: Breast cancer; Chemotherapy in pregnancy; Pregnancy; Surgery in pregnancy

\section{Epidemiology of breast cancer in pregnancy}

It is estimated that 1 in 3000 pregnancies are complicated by breast cancer, and the incidence is expected to rise as more women in developed countries delay childbearing until later in life [1-5]. There is no consensus in the literature as to what comprises 'pregnancy-associated breast cancer', with some authors including only breast cancers diagnosed in women who are pregnant at the time of diagnosis, and others also including breast cancers diagnosed within a year postpartum or during lactation.

\section{Principles of treating breast cancer in pregnant women}

An appreciation of the stages of in utero development is critical to the appropriate management of

\footnotetext{
Correspondence to: Dr Gurdip K. Azad, MRCP, MD, Guy's Hospital, St Thomas Street, London SE1 9RT, UK. E-mail: gurdip.azad@gstt.nhs.uk; Tel: +440207 1887188 Ext. 1646

Received: $15 / 08 / 07$ Accepted: 21/08/07 BCO/650/2007/FO
}

these patients. Implantation usually occurs within two weeks following conception. In humans the internal organs develop their structure within the third to eighth weeks in utero (the period of organogenesis). Insults, pharmacological or physical, to the foetus during this period may manifest as major malformations, or as foetal loss. However, after the first trimester organogenesis is complete and the risks of major malformations are minimal, although it should be recognised that the gonads and the central nervous system continue to develop later in foetal life. The rest of uterine life largely consists of growth and maturation of the foetus, processes that appear to be less-obviously susceptible to the effects of pharmacological and physical damage.

\section{Diagnosing breast cancer in pregnant women}

As for non-pregnant women, the diagnostic pathway should comprise clinical examination, imaging and pathological assessments. However, during pregnancy, clinical breast examination can be difficult as the breasts become firmer and more nodular as a result of glandular proliferation. Mammograms 
are often not performed, not just because of concerns regarding harm to the foetus from ionising radiation, but also because the increased breast density in pregnancy makes them more difficult to interpret. (However, it should be recognised that mammography may identify extensive microcalcifications, a finding that may alter management if a wide-local excision is being considered.) Ultrasound is more frequently used as the imaging modality of choice, particularly as most women present with a lump. There is very limited data concerning the utility of magnetic resonance imaging (MRI) to diagnose primary breast cancers, and there are difficulties with positioning the patient prone and concerns regarding the safety of gadolinium contrast agent [6].

Staging investigations should be carried out where appropriate, taking into consideration the risks to the foetus and the extent to which a positive result will immediately effect management. The issue of exposure to ionising radiation in pregnancy is one which creates a great deal of concern among physicians and patients, but in fact when one considers chest $\mathrm{X}$-rays and mammograms the risks are probably minimal $[7,8]$. However, CT scans may expose the foetus to higher doses of radiation and are usually avoided. Metastases may be sought using other imaging modalities such as ultrasonography or MRI [9].

\section{Histopathological features of breast cancer in pregnancy}

In pregnant women, the histopathological and immunohistochemical findings of breast cancer are found to be similar to those of non-pregnant young women, indicating that the biological features of the cancer are most likely determined by the age of the patient at diagnosis [10]. A large proportion of the tumours diagnosed during pregnancy are high grade, display lymphovascular invasion and involve the axillary lymph nodes [10-12]. Approximately $60-80 \%$ of breast cancers during pregnancy are reported to be oestrogen receptor (ER) negative and between $28 \%$ and $58 \%$ are said to be HER2 positive [13]. These features are similar to those we would expect in pre menopausal non-pregnant women.

\section{Treatment of pregnancy-associated breast cancer}

The treatment of a woman diagnosed with breast cancer while pregnant presents a challenge to all of those involved in their care. The data we currently use to make management decisions in pregnancyassociated breast cancer are incomplete and continue to evolve. However it is possible to draw some conclusions from the information that we do have. The treatment offered depends on the stage of the cancer, the gestational age at first presentation and patient preferences.

\section{Surgery}

Surgery is the first line of treatment for most women with breast cancer, including those who are pregnant. Breast surgery, including general anaesthesia, can be performed with minimal risk to the foetus at all stages of pregnancy $[14,15]$. Historically, most pregnant women were offered a mastectomy owing to high local recurrence rates and in the hope of avoiding adjuvant radiotherapy, which is relatively contraindicated in pregnancy $[12,16]$. However, increasingly young women are offered postoperative adjuvant chemotherapy while pregnant with radiotherapy delayed until after delivery, meaning that breast-conserving surgery has become a reasonable option. An alternative approach is to offer neoadjuvant medical therapy in pregnancy and delay surgery until postpartum [17,18]. Depending on gestational age and patient preferences, this may be a very reasonable option. The safety of sentinel lymph node biopsy in pregnancy is unknown. Some studies suggest that the amount of radiation delivered through the use of technetium for a sentinel node biopsy is as low as $4.3 \mathrm{mGy}$ and could be offered to patients $[19,20]$.

\section{Systemic treatment}

Data on the use of chemotherapy during pregnancy are limited to case reports and small case series. It appears that most anti-neoplastic drugs have the potential to cross the placenta, and by virtue of their mechanism of action could potentially harm the foetus. A second major consideration is that physiological changes associated with pregnancy affect drug pharmacokinetics and complicate correct dosing of chemotherapy agents, such that not only may the foetus be put at even greater risk but also the mother may not be treated optimally.

One might predict from knowledge of in utero development that the foetus would be at greatest risk of harm in the first trimester, and in particular during organogenesis. Indeed, when chemotherapy is given during the first trimester, the risk of malformations is approximately $10-20 \%$ [21-23]. However, when chemotherapy is administered in the third trimester, the rate of congenital malformations has been reported as approximately $3 \%$, which is similar to the baseline population risk of major malformations [24]. Hence, chemotherapy 
is usually avoided during the early embryonic period due to potential damage to the foetus. Chemotherapy-related problems are not just restricted to intra-uterine life, there can be a potential risk of sepsis and haemorrhage if the mother develops bone marrow suppression secondary to treatment and then delivers the baby. Neonatal cytopenias have been reported concomitantly with maternal low blood counts, which can pose a significant risk for the newborn [25]. Hence, delivering chemotherapy even in the second and third trimesters can sometimes prove potentially dangerous.

The regimens for which the most information is available are the anthracycline-based regimens. The MD Anderson series is a prospective body of evidence which shows that fluorouracil, Adriamycin and cyclophosphamide (FAC) chemotherapy can be given in the second/third trimester of pregnancy with minimal risk to the foetus, assuming that chemotherapy is not administered around the time of delivery [26]. There is minimal data available concerning the use of taxanes in pregnancy-associated breast cancer, but a handful of case reports indicate no greater risk with use of taxane-based preparations $[13,27]$. The potential implications of in utero chemotherapy exposure for long-term neurological, educational and cardiac development in the offspring, and also in the fertility of the offspring, are unknown. It is incumbent upon us to continue to improve the limited knowledge we have regarding this issue. The way to tackle this situation is through observation and reassessment of outcomes of pregnant women who received chemotherapy for breast cancer through national and international registry studies.

Trastuzumab has been used in the treatment of pregnancy-associated breast cancer without any adverse effects [28], and with reversible anhydramnios and renal failure [29]. However, the longterm implications of exposure to this and other targeted treatments in pregnancy are unclear [30]. Hormonal treatment, if indicated, is usually deferred until after delivery. Some case reports highlight the safe delivery of tamoxifen in metastatic breast cancer $[31,32]$, whereas others report birth defects like Goldenhar syndrome [33] and ambiguous genitalia [34].

Medications like anti-emetics and steroids can usually be administered during the course of chemotherapy without any adverse effects [35]. 5HT3 antagonists like ondansetron have not been reported to cause any malformations [36,37]. One casecontrol study has highlighted the association between the use of corticosteroids in the first trimester and the occurrence of cleft palate in the newborn; hence, steroids should probably be avoided in the first trimester [38]. Granulocyte colony-stimulating factors (GCSF) and erythropoietin have been safely used in pregnancy and the current recommendations for the use of white blood cell growth factors should be followed $[39,40]$.

\section{Radiotherapy}

As with any ionising radiation exposure, there is the risk with radiotherapy of inducing foetal loss, malformations or growth retardation. In the treatment of breast cancer, a standard dose of 50-60 Gy is used to radiate the breast tissue/chest wall and the foetus could receive up to $2 \mathrm{cGy}$ in the first trimester, $24.6 \mathrm{cGy}$ in the second trimester and up to $58.6 \mathrm{cGy}$ in the third trimester [7]. Radiation doses of 1090 cGy have been associated with detrimental consequences [41]. Therefore in pregnancy-associated breast cancer radiotherapy is usually deferred till after delivery. However, there have been some reported cases of radiotherapy use in pregnant breast cancer patients [42]. Under these circumstances, the potential of radiotherapy to harm the foetus has to be weighed up against improvements in recurrence-free survival and overall mortality from breast cancer.

\section{Genetic counselling}

Up to $10 \%$ of breast cancers have an inherited basis. These cancers may occur as a result of inheriting an altered BRCA1 or BRCA2 gene. Women with a mutation in either gene are at an increased risk for early-onset breast cancer, bilateral breast cancer and ovarian cancer. Women with pregnancy-associated breast cancer have an increased risk for these predisposing mutations, hence genetic counselling is recommended for all these women. In one Swedish study, more women with pregnancy-associated breast cancers had a BRCA1 mutation rather than a BRCA2 mutation [43]. Genetic counselling combined with genetic testing may help women to make important decisions about medical care and cancer screening.

\section{Psychological counselling}

The diagnosis of breast cancer during pregnancy will certainly cause shock, anxiety and depression to any woman and the members of her family. Patients should be offered the opportunity to discuss some of the complex decisions in a supportive environment with a skilled counsellor, especially if they have difficulty coping with making major life decisions sooner than expected. Also, getting such women in contact with other younger women who have pregnancyassociated breast cancer may help. 


\section{Prognosis of breast cancer in pregnancy}

Historically, pregnancy-associated breast cancer has been assumed to have a particularly poor prognosis, with 5 -year survivals in the region of 20-30\%. However, initial case series were not necessarily compared with appropriate matched control cases, taking into account important patient and pathological variables, such as young age, grade of tumour and ER status. Where this has been done, and if one makes allowances for the fact that many of these women did not receive optimal treatment, there is probably little difference in survival between pregnancy-associated and nonpregnancy-associated breast cancer [44-46].

\section{Discussion}

The treatment of women with breast cancer diagnosed in pregnancy poses a unique challenge to the health care professionals involved in their care. Treatment should be instigated by the multidisciplinary team such that a consensus to management is made. Initial investigations can be carried out as for non-pregnant women bearing in mind the adverse effects of ionising radiation to the foetus. Surgery can be carried out without much risk, but radiotherapy is generally avoided. Chemotherapy can be administered safely after the first trimester but is avoided around the time of delivery in order to prevent complications related to cytopenias. Under these circumstances there is little evidence to suggest that chemotherapy has significant short-term implications for the foetus or the mother, but the long-term implications of such exposure remain unknown.

\section{References}

1. Anderson JM. Mammary cancers and pregnancy. BMJ 1979; 1: 1124-1127.

2. White TT. Prognosis of breast cancer for pregnant and nursing women: analysis of 1413 cases. Surg Gynecol Obstet 1955; 100: 661-666.

3. Smith LH, Dalrymple JL, Leiserowitz GS, Danielsen B, Gilbert WM. Obstetrical deliveries associated with maternal malignancy in California, 1992 through 1997. Am J Obstet Gynecol 2001; 184: 1504-1513.

4. American Cancer Society. Cancer Facts \& Figures 2006. Available at www.cancer.org.

5. Ventura SJ. First birth to older mothers, 1970-86. Am J Public Health 1989; 79: 1675-1677.

6. Shellock FG, Kanal E. Safety of magnetic resonance imaging contrast agents. J Magn Reson Imaging 1999; 10: 477-484.

7. Mazonakis $\mathrm{M}$, Varveris $\mathrm{H}$, Damilakis $\mathrm{J}$, et al. Radiation dose to conceptus resulting from tangential breast irradiation. Int J Radiat Oncol Biol Phys 2003; 55: 386-391.
8. Sharp C, Shrimpton JC, Bury RF. Diagnostic Medical Exposures: Advice on Exposure to lonizing Radiation During Pregnancy. London, UK: National Radiological Protection Board, 1998. ISBN-0-85951-420-X.

9. Osei EK, Faulkner K. Fetal doses from radiological examinations. Br J Radiol 1999; 72: 773-780.

10. Middleton LP, Amin M, Gwyn K, et al. Breast carcinoma in pregnant women: assessment of clinicopathologic and immunohistochemical features. Cancer 2003; 98: 1055-1060.

11. Shousha S. Breast carcinoma presenting during or shortly after pregnancy and lactation. Arch Pathol Lab Med 2000; 124: 1053-1060.

12. Ishida T, Yokoe T, Kasmu F, et al. Clinicopathologic characteristics and prognosis of breast cancer patients associated with pregnancy and lactation: analysis of case control study in Japan. Jpn J Cancer Res 1992; 83: 1143-1149.

13. Ring A, Smith IE, Ellis PA. Breast cancer in pregnancy. Ann Oncol 2005; 16: 1855-1860.

14. Mazze RI, Kallen B. Reproduction outcome after anaesthesia and operation during pregnancy: a registry study of 5405 cases. Am J Obstet Gynecol 1989; 161: 1178-1185.

15. Duncan PG, Pope WDG, Cohen MM, Greer N. Foetal risk of anaesthesia and surgery during pregnancy. Anaesthesiology 1986; 64: 790-794.

16. Berry DL, Theriault RL, Holmes FA, et al. Management of breast cancer during pregnancy using a standardized protocol. J Clin Oncol 1999; 17: 855-861.

17. Kuerer HM, Gwyn K, Ames FC, Theriault RL. Conservative surgery and chemotherapy for breast carcinoma during pregnancy. Surgery 2002; 131: 108-110.

18. Kaufmann M, von Minckwitz G, Smith R, et al. International expert panel on the use of primary (preoperative) systemic treatment of operable breast cancer: review and recommendations. J Clin Oncol 2003; 21: 2600-2608.

19. Gentilini O, Cresmonesi M, Trifiro G, et al. Safety of sentinel node biopsy in pregnant patients with breast cancer. Ann Oncol 2004; 15: 1348-1351.

20. Keleher A, Wendt 3rd R, Delpassand E, Stachowiak AM, Kuerer HM. The safety of lymphatic mapping in pregnant breast cancer patients using Tc-99m sulphur colloid. Breast J 2004; 10: 492-495.

21. Doll DC, Ringenberg QS, Yarbro JW. Antineoplastic agents in pregnancy. Semin Oncol 1989; 16: 337-346.

22. Ebert U, Loffler H, Kirch W. Cytotoxic therapy and pregnancy. Pharmacol Ther 1997; 74: 207-220.

23. Woo JC, Yu T, Hurd TC. Breast cancer in pregnancy: a literature review. Arch Surg 2003; 138: 91-98.

24. Kalter $\mathrm{H}$, Warkany J. Congenital malformations etiologic factors and their role in prevention. Parts I and II. N EngI J Med 1983; 308: 424-431, 491-497.

25. Giacalone PL, Laffargue F, Benos P. Chemotherapy for breast carcinoma during pregnancy: a French national survey. Cancer 1999; 86: 2266-2272.

26. Hahn KME, Johnson PH, Gordon N, et al. Treatment of pregnant breast cancer patients and outcomes of children exposed to chemotherapy in utero. Cancer 2006; 107: 1219-1226. 
27. Potluri V, Lewis D, Burton GV. Chemotherapy with taxanes in breast cancer during pregnancy: case report and review of literature. Clin Breast Cancer 2006; 7: 167-170.

28. Lee KF, Simon H, Chen H, Bates B, Hung MC, Hauser C. Requirement for neuregulin receptor erbB-2 in neural and cardiac development. Nature 1995; 378: 394-398.

29. Bader AA, Schlembach D, Tarnussino KF, Pristauz G, Petru E. Anhydramnios associated with administration of trastuzumab and paclitaxel for metastatic breast cancer during pregnancy. Lancet Oncol 2007; 8: 79-81.

30. Robinson AC, Watson WJ, Leslie KJ. Targeted treatment using monoclonal antibodies and tyrosine-kinase inhibitors in pregnancy. Lancet Oncol 2007; 8: 738-743.

31. Oksuzoglu B, Guler N. An infertile patient with breast cancer who delivered a healthy child under adjuvant tamoxifen therapy. Eur J Obstet Gynecol Reprod Biol 2002; 104: 79.

32. Isaacs RJ, Hunter W, Clark K. Tamoxifen as systemic treatment of advanced breast cancer during pregnancy - case report and literature review. Gynecol Oncol 2001; 80: 405-408.

33. Cullins SL, Pridjian G, Sutherland CM. Goldenhars syndrome associated with tamoxifen given to a mother during gestation. JAMA 1994; 271: 1905-1906.

34. Tewari K, Bonebrake RG, Asrat T, Shanberg AM. Ambiguous genitalia in infant exposed to tamoxifen in utero. Lancet 1997; 350: 183.

35. Gralla RJ, Osoba D, Kris MG, et al. Recommendations for the use of anti-emetics: evidence based, clinical practice guidelines. J Clin Oncol 1999; 17: 2971-2994.

36. Tincello DG, Johnstone MJ. Treatment of hyperemesis gravidarum with the $5 \mathrm{HT} 3$ antagonist ondansetron. Postgrad Med J 1996; 72: 688-689.
37. Sullivan CA, Johnson CA, Roach H, Martin RW, Stewart DK, Morrison JCA. pilot study of intravenous ondansetron for hyperemesis gravidarum. Am J Obstet Gynecol 1996; 174: 1565-1568.

38. Rodriguez-Pinilla E, Martinez-Frias ML. Corticosteroids during pregnancy and oral clefts: a case control study. Teratology 1998; 58: 2-5.

39. Briggs GC, Freeman RK, Yaffee SM. A Reference Guide to Fetal and Neonatal Risk: Drugs in Pregnancy and Lactation. Philadelphia: Lippincott Williams \& Wilkins, 1998.

40. Smith TJ, Khatcheressian J, Lyman GH, et al. 2006 update of recommendations for the use of white blood cell growth factors: an evidence-based clinical practice guideline. J Clin Oncol 2006; 19: 3187-3205.

41. National commission on radiological protection. Pregnancy and medical radiation. Ann IRCP 2000; 30.

42. Antypas C, Sandiols P, Kouvaris J, et al. Fetal dose evaluation during breast cancer radiotherapy. Int $J$ Radiat Oncol Biol Phys 1998; 40: 995-999.

43. Johannson O, Loman N, Borg A, Ollson H. Pregnancy associated breast cancer in BRCA1 and BRCA2 germline mutation carriers. Lancet 1998; 352: 1359-1360.

44. Bonnier P, Romain S, Dilhuydy JM, et al. Influence of pregnancy on the outcome of breast cancer: a casecontrol study. Int J Cancer 1997; 72: 720-727.

45. Zemlickis D, Lishner M, Degendorfer P, et al. Maternal and foetal outcome after breast cancer in pregnancy. Am J Obstet Gynecol 1992; 166: 781-787.

46. Aziz S, Pervez S, Khan S, et al. Case control study of novel prognostic markers and disease outcome in pregnancy/lactation associated breast carcinoma. Pathol Res Pract 2003; 199: 15-21. 